\title{
Synthesis and Guest-Binding Behavior of Water-Soluble Cyclophanes Bearing PEG Residues
}

\author{
Osamu Hayashida*, Yuki Nakamura, Takuya Sato \\ Department of Chemistry, Faculty of Science, Fukuoka University, Fukuoka, Japan \\ Email: ${ }^{*}$ hayashida@fukuoka-u.ac.jp
}

Received 26 August 2014; revised 9 September 2014; accepted 16 September 2014

Copyright (C) 2014 by authors and Scientific Research Publishing Inc.

This work is licensed under the Creative Commons Attribution International License (CC BY). http://creativecommons.org/licenses/by/4.0/

(c) (i) Open Access

\section{Abstract}

A water-soluble cyclophane (1) having poly(ethylene glycol) (PEG) moieties has been prepared from a tetraazide-functionalized cyclophane derivative and four poly(ethylene glycol) methyl ether acetylenes by $\mathrm{Cu}(\mathrm{I})$-catalyzed 1,3 dipolar cycloadditions (click chemistry). An analogous derivative having a pyrene moiety (2) was also prepared in a similar manner. The guest-binding behavior of 1 and 2 toward anionic guests such as 6-p-toluidinonaphthalene-2-sulfonate was investigated by fluorescence spectroscopy. The binding constants $(K)$ of the host-guest complexes were evaluated.

\section{Keywords}

\section{Host-Guest Chemistry, Water-Soluble Cyclophane, Poly(Ethylene Glycol)}

\section{Introduction}

Cyclophanes are macrocyclic compounds that form host-guest complexes with various organic compounds [1]. Among macrocyclic hosts, cyclophanes play a wider and prominent role in host-guest chemistry and supramolecular chemistry [2]. In aqueous media, hydrophobic interaction is the major driving force for host-guest complexation [3]. It is desirable for water-soluble cyclophanes as hosts to provide hydrophobic binding sites that can be well desolvated upon guest incorporation. Therefore, the hydrophobic internal cavity must be reasonably separated from hydrophilic groups that are required for giving water solubility to cyclophanes. In our previous study, we developed various water-soluble cyclophanes having a hydrophobic internal cavity by introducing polar side chains such as saccharide residues, ammonium, and carboxylate groups into the cyclophane skeleton

\footnotetext{
"Corresponding author.
}

How to cite this paper: Hayashida, O., Nakamura, Y. and Sato, T. (2014) Synthesis and Guest-Binding Behavior of Water-Soluble Cyclophanes Bearing PEG Residues. Advances in Chemical Engineering and Science, 4, 409-416. 
through an alkyl spacer having amide linkage [4].

On the other hand, chemical modification of poly(ethylene glycol) (PEG) to peptides or proteins is currently used to offer improved water solubility and stability [5]. In addition, PEG is generally considered biologically inert and safe [6]. In the course of our ongoing research on water-soluble cyclophanes capable of performing guest-inclusion, we became interested in developing nonionic and water-soluble cyclophanes having PEG residues. Specifically, we have designed cyclophane 1 by introducing four PEG moieties into tetraaza [6.1.6.1] paracyclophane [7] through a spacer (Figure 1). We expected that PEG could improve the surface hydrophilicity of cyclophanes. In addition, we also designed pyrene-appended cyclophane bearing three PEG residues 2 (Figure 1). Cyclophane 2 is expected to act as water-soluble fluorescent host capable of binding and sensing guest molecules. We report here the synthesis of water-soluble cyclophanes having PEG residues and their guest-binding abilities.

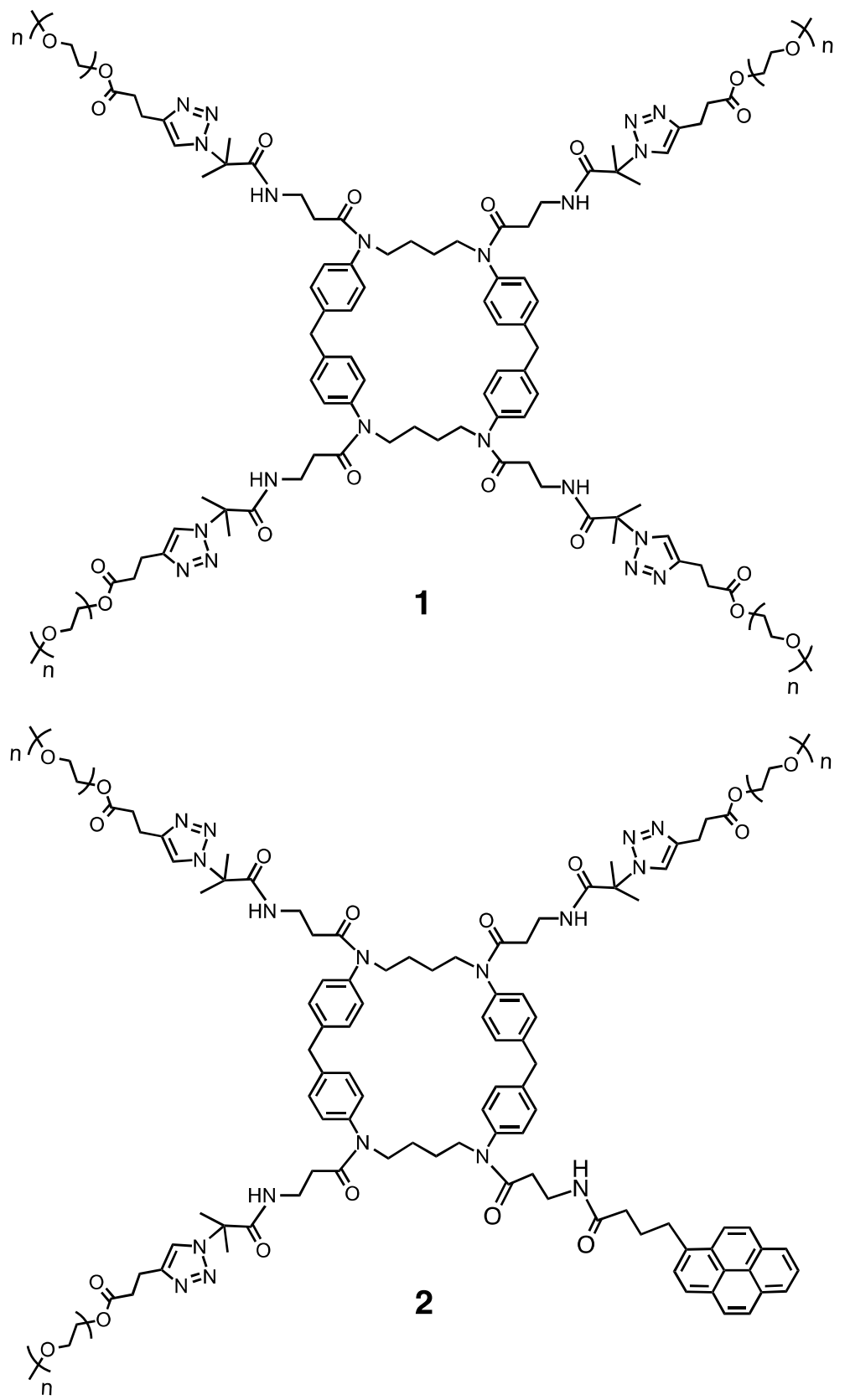

Figure 1. Water-soluble cyclophanes bearing a PEG moiety 1 and 2. 


\section{Experimental Section}

\subsection{General Methods}

HEPES ( $N$-(2-hydroxyethyl) piperazine- $N$ '-2-ethane-sulfonic acid) buffer (0.01 M, pH 7.4, with $0.15 \mathrm{M} \mathrm{NaCl})$ was purchased from GE Healthcare. The following compounds were obtained from commercial sources as guaranteed reagents and used without further purification: potassium 6-p-toluidinonaphthalene-2-sulfonate [K(TNS)] (from Nacalai Tesque, Inc., Kyoto, Japan), 6-anilinonaphthalene-2-sulfonic acid (2,6-ANS) (from Molecular Probes, Eugene, OR), poly(ethylene glycol)methyl ether acetylene (average Mn = 2000) (from Sigma-Aldrich Japan, Tokyo, Japan). A tetraazide derivative of cyclophane (3) was prepared after a method reported previously [8]. A triamine derivative of cyclophane having a pyrene moiety (4) was also prepared after a method reported previously [9]. ${ }^{1} \mathrm{H}$ and ${ }^{13} \mathrm{C}$ spectra were taken on Varian Mercury 400 spectrometer. Fluorescence spectra, IR spectra, and ESI TOF MS were recorded on JASCO FP-750, Perkin-Elmer spectrum one, and JMS-T100 CS spectrometers, respectively.

\subsection{Cyclophane Bearing PEG Moieties (1)}

A solution of anhydrous copper (II) sulfate $(3.4 \mathrm{mg}, 0.02 \mathrm{mmol})$ and sodium L-ascorbate $(4.3 \mathrm{mg}, 0.02 \mathrm{mmol})$ in distilled water $(0.5 \mathrm{ml})$ was added dropwise to the solution of poly(ethylene glycol)methyl ether acetylene (197 $\mathrm{mg}, 0.1 \mathrm{mmol})$ and tetraazide derivative of cyclophane [8] (3, $30 \mathrm{mg}, 0.02 \mathrm{mmol})$ in dry $N, N$-dimethylformamide (DMF, $3 \mathrm{ml}$ ) at room temperature, the resulting mixture was stirred for $24 \mathrm{~h}$ at room temperature. Evaporation of the solvents under reduced pressure gave a solid. After dialysis (3.5 kDa cut-off) for 7 days, the solvent was freeze-dried to give compond 1 as a white solid (193 mg, $88 \%$ ): ${ }^{1} \mathrm{H}$ NMR (400 $\left.\mathrm{MHz}, \mathrm{CDCl}_{3}, 293 \mathrm{~K}\right) \delta 1.4$ $(\mathrm{m}), 1.9(\mathrm{~m}), 2.0(\mathrm{~m}), 2.8(\mathrm{t}), 3.1(\mathrm{~m}), 3.3(\mathrm{~m}), 3.4(\mathrm{~s}), 3.5$ - $3.8(\mathrm{~m}), 3.9(\mathrm{~m}), 4.2(\mathrm{t}), 6.6(\mathrm{~m}), 7.0(\mathrm{~d}), 7.2(\mathrm{~d})$, and 7.6 (s). ${ }^{13} \mathrm{C}$ NMR (100 MHz, CDCl 3 , $\left.293 \mathrm{~K}\right) \delta 21,25,26,34,36,41,49,59,64,65,69,71,72,120,128,130$, 140, 141, 146, 171, and 173. IR $1101 \mathrm{~cm}^{-1}$ (C-O-C), 1649, $1734 \mathrm{~cm}^{-1}(\mathrm{C}=\mathrm{O})$.

\subsection{Triazide Derivative of Cyclophane Bearing A Pyrene Moiety (5)}

Solutions of $\alpha$-azidoisobutyric acid in heptane ( $1.0 \mathrm{ml}, 1.2 \mathrm{mmol}$ ) and triethylamine ( $0.25 \mathrm{ml})$ in dry DMF ( $3 \mathrm{ml})$ were added dropwise to the solution of triamine derivative of cyclophane 4 [9] (135 mg, $0.10 \mathrm{mmol}$ ), benzotriazol-1-yl-oxytripyrrolidinophosphonium hexafluorophosphate (PyBOP, $215 \mathrm{mg}, 0.41 \mathrm{mmol}$ ), in dry DMF (2 ml) at room temperature, the resulting mixture was stirred for 2 days at room temperature. Ethyl acetate (EtOAc, $200 \mathrm{ml}$ ) was added to the reaction mixture, and the mixture was then washed with saturated aqueous sodium chloride $(50 \mathrm{ml})$. After being dried $\left(\mathrm{MgSO}_{4}\right)$, the solution was evaporated to dryness under reduced pressure. The crude product was purified by gel filtration chromatography on a column of Sephadex LH-20 with methanol as an eluant. The product fraction was evaporated to dryness under reduced pressure to give a white solid. (99 mg, 72\%): ${ }^{1} \mathrm{H}$ NMR (400M Hz, $\left.\mathrm{CDCl}_{3}, 293 \mathrm{~K}\right) \delta 1.43(\mathrm{~m}), 1.49(\mathrm{~m}), 2.1(\mathrm{~m}), 2.2(\mathrm{~m}), 2.3(\mathrm{t}), 3.4(\mathrm{~m}), 3.6(\mathrm{~m})$, $3.9(\mathrm{~m}), 6.4(\mathrm{~m}), 6.9(\mathrm{~m}), 7.1(\mathrm{~m})$, and $7.3(\mathrm{~m}) .{ }^{13} \mathrm{C} \mathrm{NMR}\left(100 \mathrm{MHz}, \mathrm{CDCl}_{3}, 293 \mathrm{~K}\right) \delta 24.4,24.8,27,28,30,33$, $34,35,36,41,49,64,123,124,125,126,127,129,130,139,140,170,171$, and 172. IR 1643, $1715 \mathrm{~cm}^{-1}$ $(\mathrm{C}=\mathrm{O}), 2108 \mathrm{~cm}^{-1}(\mathrm{~N} \equiv \mathrm{N})$. ESI-TOF MS: $\mathrm{m} / \mathrm{z} 1414[\mathrm{M}+\mathrm{Na}]^{+}$.

\subsection{Pyrene-Appended Cyclophane Bearing PEG Moieties (2)}

A solution of anhydrous copper (II) sulfate ( $3.4 \mathrm{mg}, 0.02 \mathrm{mmol}$ ) and sodium L-ascorbate ( $4.3 \mathrm{mg}, 0.02 \mathrm{mmol}$ ) in distilled water $(0.5 \mathrm{ml})$ was added dropwise to the solution of poly(ethylene glycol)methyl ether acetylene (158 $\mathrm{mg}, 0.08 \mathrm{mmol})$ and triazide derivative of cyclophane $(5,30 \mathrm{mg}, 0.02 \mathrm{mmol})$ in dry DMF (3 ml) at room temperature, the resulting mixture was stirred for $24 \mathrm{~h}$ at room temperature. Evaporation of the solvents under reduced pressure gave a solid. The crude product was purified by gel filtration chromatography on a column of Sephadex LH-20 with methanol as an eluant. The product fraction was evaporated to dryness under reduced pressure to give compound 2 as a white solid. (141 mg, $95 \%):{ }^{1} \mathrm{H}$ NMR $\left(400 \mathrm{MHz}, \mathrm{CDCl}_{3}, 293 \mathrm{~K}\right) \delta 1.4(\mathrm{~m}), 1.9$ (m), $2.0(\mathrm{~m}), 2.1(\mathrm{~m}), 2.3(\mathrm{~m}), 2.8(\mathrm{~m}), 3.1(\mathrm{~m}), 3.3(\mathrm{~m}), 3.4(\mathrm{~s}), 3.4-3.8(\mathrm{~m}), 3.9(\mathrm{~m}), 4.3(\mathrm{~m}), 6.6(\mathrm{~m}), 6.9(\mathrm{~m})$, $7.1(\mathrm{~m}), 7.6(\mathrm{~m}), 7.8(\mathrm{~m}), 7.9(\mathrm{~m}), 8.1(\mathrm{~m}), 8.2(\mathrm{~m})$, and $8.3(\mathrm{~m}) .{ }^{13} \mathrm{C} \mathrm{NMR}\left(100 \mathrm{MHz}, \mathrm{CDCl}_{3}, 293 \mathrm{~K}\right) \delta 21,25$, 26, 33, 34, 36, 37, 41, 49, 59, 64, 65, 69, 71, 120, 142, 125, 126, 127, 128, 130, 131, 132, 136, 140, 141, 147, 171, 172, and 173. IR $1111 \mathrm{~cm}^{-1}$ (C-O-C), 1643, $1734 \mathrm{~cm}^{-1}$ (C=O). 


\subsection{Binding Constants of Cyclophanes with the Guests}

To each solution of a fluorescent guests $(1.0 \mu \mathrm{M})$ in HEPES buffer were added increasing amounts of the $\mathbf{1}$ at 298K, and the guest fluorescence intensity was monitored after each addition by excitation at 326 and $318 \mathrm{~nm}$ for TNS and 2,6-ANS, respectively.

To a solution of fluorescent cyclophane $2(1.0 \mu \mathrm{M})$ in HEPES buffer were added increasing amounts of TNS and 2,6-ANS, and the fluorescence intensity was monitored after each addition by excitation at $322 \mathrm{~nm}$. The binding constants were calculated on the basis of the Benesi-Hildebrand method for titration data.

\section{Results and Discussion}

\subsection{Design and Synthesis of Pyrene-Appended Cyclophanes}

$\mathrm{Cu}(\mathrm{I})$-catalyzed Huisgen's 1,3-dipolar "click" cycloaddition of an azide and an alkyne has been increasingly used in many fields such as biological [10] and materials [11]. We adopted the click reaction to synthesize the cyclophanes due to the advantages of its high efficiency, regioselectivity, and compatibility with reaction conditions. Water-soluble cyclophane bearing PEG residues $\mathbf{1}$ was synthesized by following the reaction sequence shown in Scheme 1. In the preceding paper, we have synthesized a tetraazide derivative of cyclophane 3 [8]. Then, cyclophane $\mathbf{1}$ was synthesized by click reaction between $\mathbf{3}$ and poly(ethylene glycol)methyl ether acetylene (average $\mathrm{Mn}=2000$ ) in a good yield of $88 \%$. On the other hand, triazide derivative of cyclophane 5 was synthesized by a reaction of triamine derivative of cyclophane 4 [9] with $\alpha$-azidoisobutyric acid in heptane in the
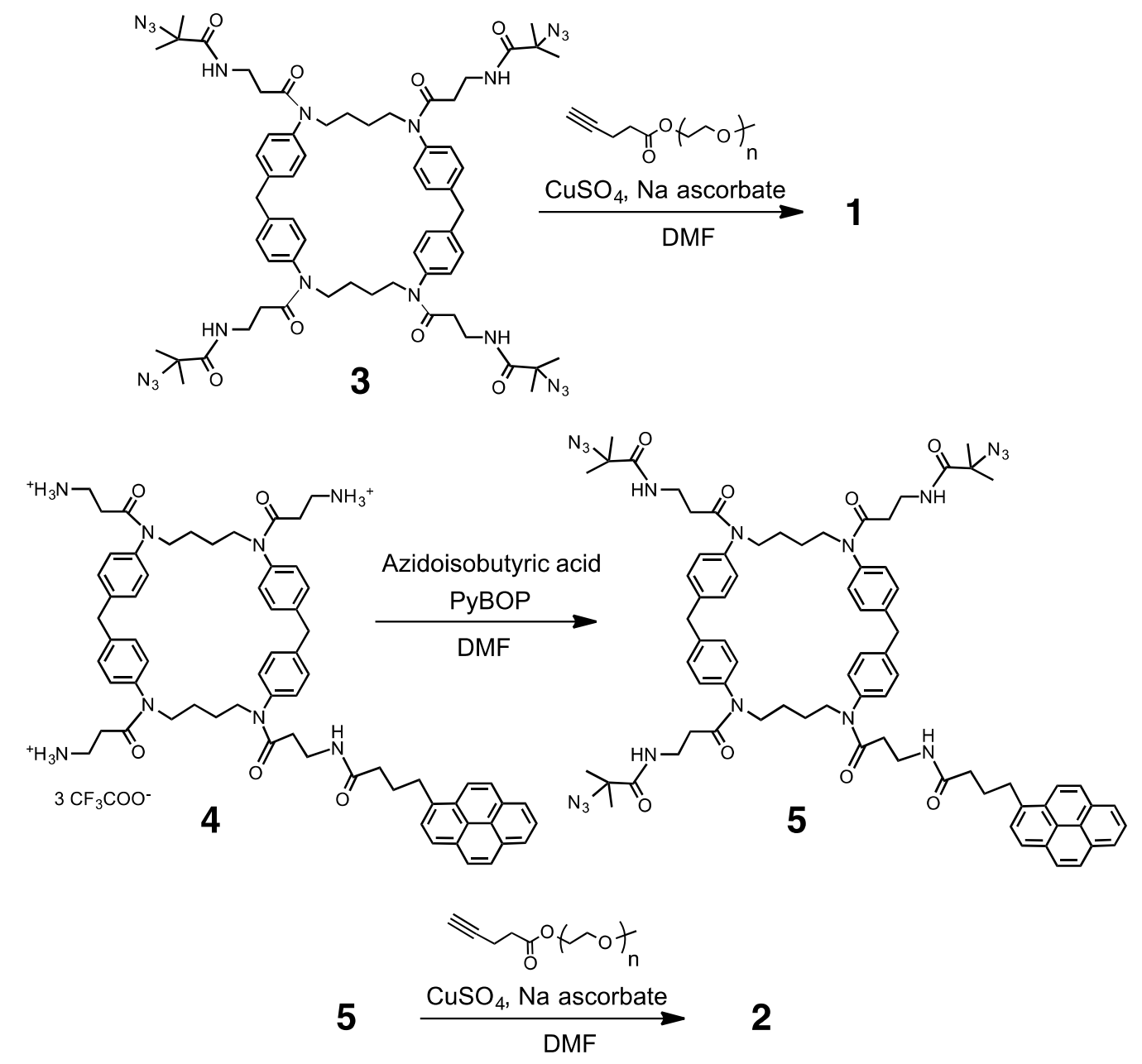

Scheme 1. Preparation of cyclophanes $\mathbf{1}$ and $\mathbf{2 .}$ 
presence of benzotriazol-1-yl-oxytripyrrolidinophosphonium hexafluorophosphate (PyBOP) (Scheme 1). Similarly, pyrene-appended water-soluble cyclophane bearing PEG residues 2 was synthesized by $\mathrm{Cu}(\mathrm{I})$-catalyzed Huisgen's 1,3-dipolar cycloaddition of $\mathbf{5}$ with poly(ethylene glycol)methyl ether acetylene (average $\mathrm{Mn}=2,000$ ) in a good yield of $95 \%$. Even though compounds $\mathbf{1}$ and $\mathbf{2}$ contain a hydrophobic cavity, both compounds were soluble in aqueous neutral media at biological pH owing to three PEG side chains. From a practical standpoint, cyclophanes 1 and 2 had good $\mathrm{H}_{2} \mathrm{O}$-solubility of 0.3 and $0.2 \mathrm{~g} / \mathrm{mL}$, respectively. Both $\mathbf{1}$ and 2 having hydrophobic cavities were expected to act as water-soluble hosts.

\subsection{Guest-Binding Behavior of Cyclophanes}

In order to evaluate guest-binding ability of $\mathbf{1}$ and $\mathbf{2}$, we adopted well-known fluorescent probes such as 6-p-toluidinonaphthalene-2-sulfonate (TNS) and 6-anilinonaphthalene-2-sulfonate (2,6-ANS), whose emission is extremely sensitive to the microenvironmental polarity of the surrounding medium in both intensity and wavelength [12]. First, the guest-binding behavior of cyclophane 1 toward TNS and 2,6-ANS was examined by fluorescence spectroscopy in aqueous HEPES (2-[4-(2-hydroxyethyl)-1-piperazinyl]ethanesulfonic acid) buffer $(0.01 \mathrm{M}, \mathrm{pH} 7.4,0.15 \mathrm{M}$ with $\mathrm{NaCl})$ at $298 \mathrm{~K}$. The fluorescence intensity originating from TNS increased along with a concomitant blue shift of the fluorescence maximum upon addition of a large excess amount of $\mathbf{1}$ as shown in Figure 2(a), showing that the guest molecules are incorporated into the hydrophobic cavity provided

(a)
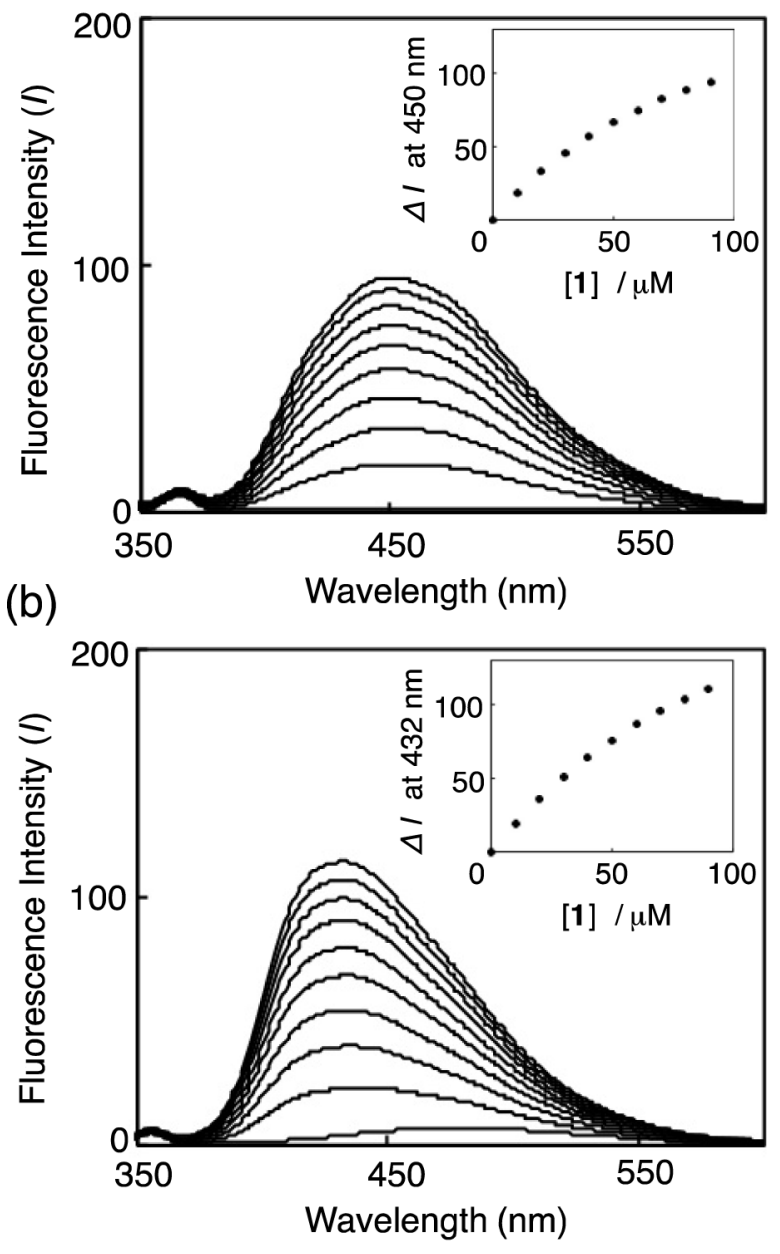

Figure 2. Fluorescence spectral changes for an aqueous solution of TNS (a) and 2,6-ANS (b) upon addition of 1 in HEPES buffer at $298 \mathrm{~K}$; [TNS $]=[2,6-\mathrm{ANS}]=1.0 \mu \mathrm{M}$. [1] $=0,10,20,30,40,50,60,70,80$, and $90 \mu \mathrm{M}$ (from bottom to top). Ex. 326 and $318 \mathrm{~nm}$ for TNS and 2,6-ANS, respectively. Inset: the corresponding titration curves. 
by $\mathbf{1}$. A similar fluorescence feature was observed when 2,6-ANS was employed as a guest for complexation with 1 (Figure 2(b)). In addition, binding constants (K) for the formation of inclusion complexes of $\mathbf{1}$ with TNS and 2,6-ANS in a 1:1 molar ratio were evaluated on the basis of the Benesi-Hildebrand relationship [13] and summarized in Table 1.

On the other hand, pyrene-appended water-soluble cyclophane 2 showed characteristic fluorescence spectra originated the pyrene moiety in aqueous media (Figure 3). The guest-binding behavior of 2 toward TNS and 2,6-ANS, was also examined by fluorescence spectroscopy in aqueous HEPES buffer (0.01 M, pH 7.4, $0.15 \mathrm{M}$ with $\mathrm{NaCl}$ ). Upon addition of TNS to an aqueous HEPES buffer containing 2 , a fluorescence intensity originated from the pyrene moiety of $\mathbf{1}$ at 376 and $396 \mathrm{~nm}$ decreased along with a concomitant increase of the fluorescence intensity of entrapped TNS molecules at around $500 \mathrm{~nm}$, as shown in Figure 3(a), reflecting the formation of host-guest complexes. Such fluorescence quenching of $\mathbf{1}$ at 376 and 396 seem to be caused by the interactions between pyrene group of $\mathbf{2}$ and entrapped TNS molecules. A similar trend of guest-binding behavior was also observed for complexation of 2 with 2,6-ANS (Figure 3(b)). The $K$ values for the 1:1 host-guest complexes
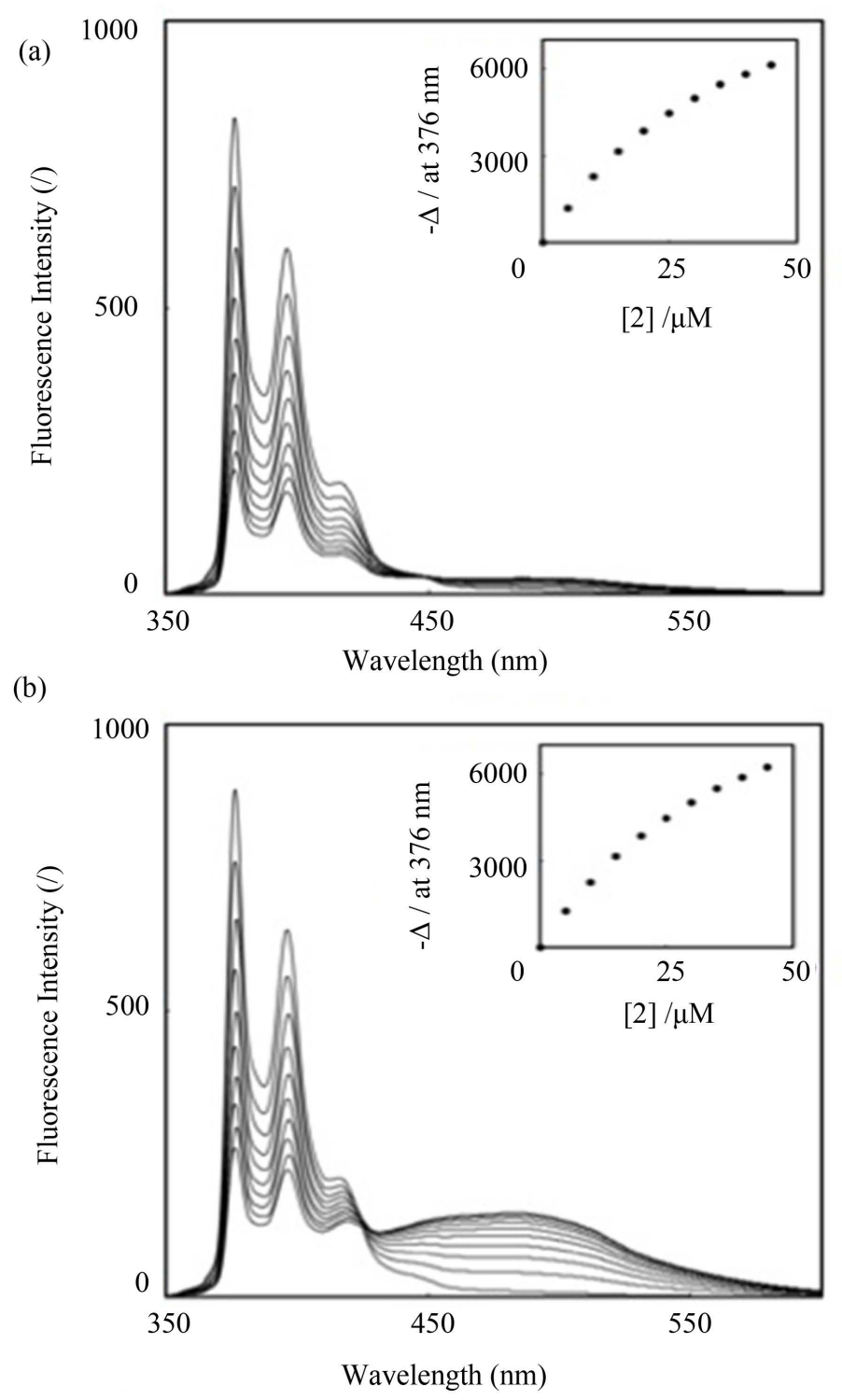

Figure 3. Fluorescence spectral changes for an aqueous solution of $\mathbf{2}$ upon addition of TNS (a) and 2,6-ANS (b) in HEPES buffer at $298 \mathrm{~K}$; [2] $=1.0 \mu \mathrm{M}$. [TNS] $=[2,6$-ANS $]=0,5,10,15,20,25,30,35,40$, and $45 \mu \mathrm{M}$ (from top to bottom at 376 $\mathrm{nm})$. Ex. $322 \mathrm{~nm}$. Inset: the corresponding titration curves. 
Table 1. Binding constants $\left(K, M^{-1}\right)$ for host-guest complexes in HEPES buffer.

\begin{tabular}{cccc}
\hline & & $K / M^{-1}$ & \\
\cline { 2 - 3 } Host & TNS & 2,6 -ANS \\
\hline $\mathbf{1}$ & $1.0 \times 10^{4}$ & $9.4 \times 10^{3}$ \\
$\mathbf{2}$ & $2.3 \times 10^{4}$ & $2.3 \times 10^{4}$ \\
\hline
\end{tabular}

were also calculated on the basis of Benesi-Hildebrand relationship and summarized in Table 1 . The $K$ values of $\mathbf{2}$ with TNS and 2,6-ANS were larger than those of $\mathbf{1}$ with the identical guests. As mentioned above, the most important driving force for host-guest comeplexation of cyclophane in aqueous media is the hydrophobic interaction. These results indicated that effective hydrophobic microenviroments were provided by 2 due to cyclophane cavity as well as a pyrene moiety.

\section{Conclusion}

We found that $\mathrm{Cu}(\mathrm{I})$-catalyzed 1,3 dipolar cycloaddition was useful to synthesize cyclophanes bearing PEG residues 1 and 2 with high efficiency. As a host, the $K$ values for 1 with TNS and 2,6-ANS were $1.0 \times 10^{4}$ and 9.4 $\times 10^{3} \mathrm{M}^{-1}$, respectively. On the other hand, 2 showed fluorescence bands with fluorescence maximum at $376 \mathrm{~nm}$ in an aqueous HEPES buffer. Formation of the host-guest complexes of 2 with the identical guests was demonstrated by fluorescence quenching experiments. The $K$ values for 2 with TNS and 2,6-ANS were $2.3 \times 10^{4}$ and $2.3 \times 10^{4} \mathrm{M}^{-1}$, respectively, which were larger than those of $\mathbf{1}$ with the identical guests, reflecting the effective hydrophobic interactions.

\section{Acknowledgements}

The present work is partially supported by Grant-in-Aid (No. 24550166) from the Ministry of Education, Culture, Science, Sports and Technology of Japan.

\section{References}

[1] Ramaiah, D., Neelakandan, P.P., Nair, A.K. and Avirah, R.R. (2010) Functional Cyclophanes: Promising Hosts for Optical Biomolecular Recognition. Chemical Society Reviews, 39, 4158-4168. http://dx.doi.org/10.1039/b920032k

[2] Ariga, K., Ito, H., Hill, J.P. and Tsukube, H. (2012) Molecular Recognition: From Solution Science to Nano/Materials Technology. Chemical Society Reviews, 41, 5800-5835. http://dx.doi.org/10.1039/c2cs35162e

[3] Hayashida, O. and Hamachi, I. (2004) Fluorophore Appended Saccharide Cyclophane: Self-Association, Fluorescent Properties, Heterodimers with Cyclodextrins, And Cross-Linking Behavior with Peanut Agglutinin of Dansyl-Modified Saccharide Cyclophane. The Journal of Organic Chemistry, 69, 3509-3516.

[4] Hayashida, O. and Kaku, Y. (2013) Synthesis of Dabsyl-Appended Cyclophanes and Their Heterodimer Formation with Pyrene-Appended Cyclophanes. The Journal of Organic Chemistry, 78, 10437-10442. http://dx.doi.org/10.1021/jo4018843

[5] Castelletto, V., McKendrick, J.E., Hamley, I.W., Olsson, U. and Cenker, C. (2010) PEGylated Amyloid Peptide Nanocontainer Delivery and Release System. Langmuir, 26, 11624-11627. http://dx.doi.org/10.1021/la101806z

[6] Xin, H., Sha, X., Jiang, X., Zhang, W., Chen, L. and Fang, X. (2012) Anti-Glioblastoma Efficacy and Safety of Paclitaxel-Loading Angiopep-Conjugated Dual Targeting PEG-PCL Nanoparticles. Biomaterials, 33, 8167-8176. http://dx.doi.org/10.1016/j.biomaterials.2012.07.046

[7] Odashima, K., Itai, A., Iitaka, Y. and Koga, K. (1985) Biomimetic Studies Using Artificial Systems. 3. Design, Synthesis, and Inclusion Complex Forming Ability of a Novel Water-Soluble Paracyclophane Possessing Diphenylmethane Skeletons. The Journal of Organic Chemistry, 50, 4478-4484. http://dx.doi.org/10.1021/jo00223a013

[8] Hayashida, O. and Nakamura, Y. (2013) Synthesis of Water-Soluble Cyclophane Pentamers Using Click Chemistry as a Multivalent Host for Daunorubicin and Doxorubicin. Bulletin of the Chemical Society of Japan, 86, 223-229. http://dx.doi.org/10.1246/bcsj.20120296

[9] Hayashida, O., Eguchi, C., Kimura, K., Oyama, Y. and Shioji, K. (2010) Guest Binding, Cellular Uptake, and Molecular Delivery of Water-Soluble Cyclophanes Having a Pyrene Moiety. Chemistry Letters, 39, 321-1322.

[10] Kappe, C.O. and Eycken, E.V. (2010) Click Chemistry Under Non-Classical Reaction Conditions. Chemical Society 
Reviews, 39, 1280-1290. http://dx.doi.org/10.1039/b901973c

[11] Zhang, K., Lackey, M.A. Wu, Y. and Tew, G.N. (2011) Universal Cyclic Polymer Templates. Journal of the American Chemical Society, 133, 6906-6909. http://dx.doi.org/10.1021/ja2007559

[12] Slavik, J. (1982) Anilinonaphthalene Sulfonate as a Probe of Membrane Composition And Function. Biochimica et Biophysica Acta - Reviews on Biomembranes, 694, 1-25.

[13] Hayashida, O., Ogawa, N. and Uchiyama, M. (2007) Surface Recognition and Fluorescence Sensing of Histone by Dansyl-Appended Cyclophane-Based Resorcinarene Trimer. Journal of the American Chemical Society, 129, 1369813705. http://dx.doi.org/10.1021/ja074906h 
Scientific Research Publishing (SCIRP) is one of the largest Open Access journal publishers. It is currently publishing more than 200 open access, online, peer-reviewed journals covering a wide range of academic disciplines. SCIRP serves the worldwide academic communities and contributes to the progress and application of science with its publication.

Other selected journals from SCIRP are listed as below. Submit your manuscript to us via either submit@scirp.org or Online Submission Portal.

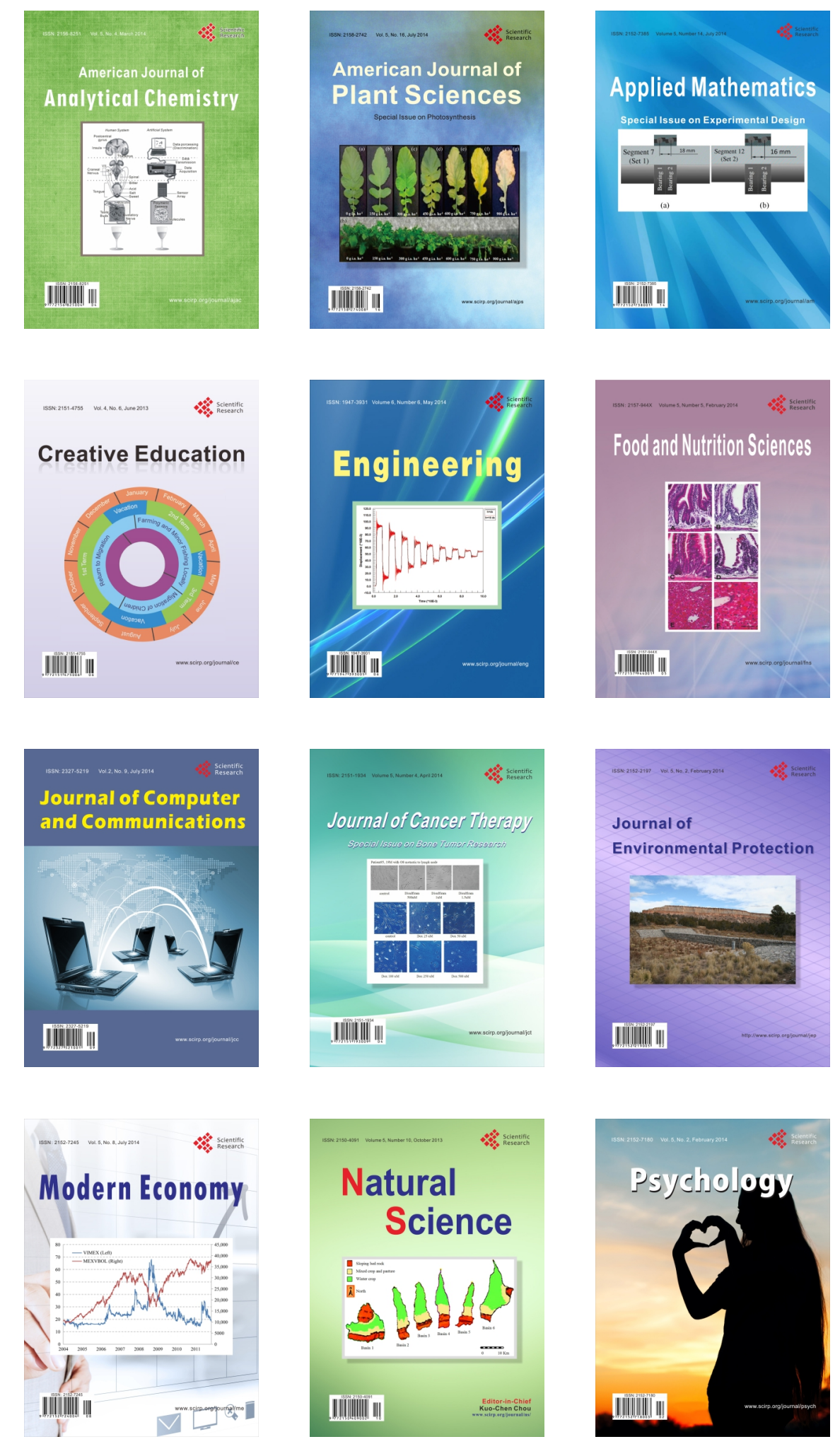